Association for Information Systems AIS Electronic Library (AISeL)

PACIS 2000 Proceedings

Pacific Asia Conference on Information Systems

(PACIS)

December 2000

\title{
A Conceptual Model for Virtual Organizational Learning
}

Fu-ren Lin

National Sun Yat-sen University

Sheng-Cheng Lin

National Sun Yat-sen University

Follow this and additional works at: http://aisel.aisnet.org/pacis2000

\section{Recommended Citation}

Lin, Fu-ren and Lin, Sheng-Cheng, "A Conceptual Model for Virtual Organizational Learning" (2000). PACIS 2000 Proceedings. 62. http://aisel.aisnet.org/pacis2000/62

This material is brought to you by the Pacific Asia Conference on Information Systems (PACIS) at AIS Electronic Library (AISeL). It has been accepted for inclusion in PACIS 2000 Proceedings by an authorized administrator of AIS Electronic Library (AISeL). For more information, please contact elibrary@aisnet.org. 


\title{
A Conceptual Model for Virtual Organizational Learning
}

\author{
Fu-ren Lin, Sheng-cheng Lin \\ Department of Information Management \\ National Sun Yat-sen University \\ Kaohsiung Taiwan, 804 \\ R.O.C
}

\begin{abstract}
On the trend of emerging virtual organizations in electronic commerce era, how to leverage knowledge through value chain in a virtual organization is essential to sustain its performance. Learning in a virtual organization is the key to achieve agility of a virtual organization; however, few studies are focused on this dimension. Therefore, this paper attempts to bring insights of learning in a virtual organization by developing a conceptual model for virtual organizational learning (VOL) based on transactive memory. The VOL model is centered by transactive memory, which is composed of knowledge maps, social networks, and mnemonic functions. The initialization of modeling learning in virtual organizations in this paper has been erecting the foundation of VOL systems in cyber communities of various domains.
\end{abstract}

Keywords: virtual organization, organizational learning, organizational memory, transactive memory, knowledge map, social network, mnemonic function, cyber community.

\section{Introduction}

As we are marching into $21^{\text {st }}$ century, a knowledge economy era, an organization's competitive advantage lies in the excellent learning capability. Organizations should learn to be agile in order to thrive in an environment with continually and unpredictably changing market opportunities. Agility can be defined in four dimensions: efficiency, flexibility, robustness, and adaptation (Lin and Shaw, 1998). A growing number of virtual organizations show the necessity in developing strategies in managing virtual organizations. It includes the building of learning capability within a virtual organization.

A virtual organization is an opportunity-pulled and opportunity-defined integration of core competencies distributed among a number of real organizations. It reflects and facilitates three major motives of agile competition: (1) to create or assemble new productive resources very quickly, (2) to create or assemble new productive resources frequently and concurrently because of the decreasing profitable lifetimes of individual products and services, and (3) to reflect the complexity of today's most profitable products, which often require access to a wider range of world-class core competencies, and then afford to maintain "in between" customer opportunities or can identify in advance of unanticipated opportunities (Goldman, Nagel, and Preiss, 1995).

Besides the above motivations, Strader, Lin, and Shaw (1998) further concluded several advantages of virtual organizational structure, such as

(1) Agility of a small company: There are less levels of bureaucracy which allows the inter-firm alliance to react more quickly. Also, these firms will be more specialized to a particular task.

(2) Resources of a large company: The resources available to a firm working as a partner in 
a virtual organization may be greater than the sum of all of the resources of the partner firms.

(3) Concentration on partners' core competences: Virtual organization partnerships will be able to have improved efficiency and effectiveness through firm specialization. This specialization may result in a synergistic situation where the overall alliance has much better performance than the sum of the individual partner's separate performances.

(4) Ability to globalize: Firms that want to take advantage of a global market opportunity can ally themselves with a firm that has expertise or market share in a given region or country.

Core competencies are the two or three most tangible, value-added activities that distinguish one company from its competitors and provide access to a variety of markets and opportunities (Bottoms, 1994). In fact, each member of the virtual organization is chosen because it brings something unique that is needed to meet a customer opportunity. Virtual organizations focus on identifying critical core competencies in which they must maintain world-class skills in order to succeed, and they will acquire ancillary core competencies as needed from partners. Questions frequently asked are how physically distributed and complementary competencies can remain dispersed in a virtual organization and still be synthesized into a coherent productive resource, and how to link core competencies quickly and concurrently in a virtual organization.

A virtual organization goes through four distinct phases, identification, formation, operation, and termination, during their life cycle as shown in Figure 1 (Strader, Lin \& Shaw, 1998). The identification phase involves opportunity identification, and opportunity evaluation and selection. The formation phase include the major decision processes of partner identification, partner evaluation and selection, and partnership formation. The operation phase generally involves five different major decision processes including design, marketing, financial management, manufacturing and distribution. The termination phase include operation termination and asset dispersal.

\begin{tabular}{|c|c|c|c|}
\hline Identification & Formation & Operation & Termination \\
\hline $\begin{array}{c}\text { Opportunity } \\
\text { Identification } \\
\text { Opportunity } \\
\text { Selection }\end{array}$ & $\begin{array}{c}\text { Partner } \\
\text { Identification } \\
\text { Partner } \\
\text { Selection } \\
\text { Partnership } \\
\text { Formation }\end{array}$ & $\begin{array}{c}\text { Design } \\
\text { Marketing } \\
\text { Financial Mgmt. } \\
\text { Manufacturing } \\
\text { Distribution } \\
\end{array}$ & $\begin{array}{c}\text { Operation } \\
\text { Termination } \\
\text { Asset } \\
\text { Dispersal }\end{array}$ \\
\hline \multicolumn{4}{|c|}{ Information Infrastructure } \\
\hline
\end{tabular}

Figure 1. The Life Cycle of a Virtual Organization (Strader, Lin, and Shaw, 1998)

Goldman et al. (1995) find that organizations must create an environment for thinking and learning in order to succeed as an agile competitor. Shenkar and Li (1999) also classify two types of organizational knowledge, compatibility and complementarity, when seeking knowledge from prospective partners. Firms seek additional knowledge in the same domain 
in which they have the prior knowledge. It requires absorptive capability where prior knowledge permits the assimilation and exploitation of new knowledge (Cohen and Levinthal, 1990). On the other hand, firms may seek knowledge in a complementary area, and thus implies synergy of diverse resources. Balakrishnan and Koza (1993) also view assets as complementary when they represent different phases in a value chain and require coordination.

Synthesizing Shenkar and Li's viewpoint (1999) and Goldman, Nagel, and Preiss' strategic reasons of formation of virtual organization (1995), we can identify the two types of knowledge linkages between participants of a virtual organization as compatible and complementary knowledge bases. This classification will help us to understand the role of our model of virtual organizational learning in relation to virtual organizations.

However, few studies have been focusing on memory and learning of inter-organizational dimension, and none on virtual organizations as shown in Table 1. Table 1 lists the literature in organizational learning and memory based on four dimensions of ontology: individual, group, organization, and inter-organization. From Table 1 we can find that all works in the inter-organization dimension focus on joint ventures and strategic alliances. From virtual organization to joint venture, the incentive to take risks decreases, the ability to settle conflicts and coordinate activities increases, and the degree of centralization increases (Chesbrough and Teece, 1996). Besides, the life cycle, number of participants, and the role of information technology (IT) are different among these three inter-organizational collaborations. Therefore, it is imperative for this research to develop a learning model for a virtual organization.

Table 1. Selective Literatures of Studying Memory and Learning

\begin{tabular}{|c|c|c|c|c|c|c|}
\hline \multirow{2}{*}{ Topic } & \multirow[b]{2}{*}{ Individual } & \multirow[b]{2}{*}{ Group } & \multirow[b]{2}{*}{ Organization } & \multicolumn{3}{|c|}{ Inter-Organization } \\
\hline & & & & $\begin{array}{c}\text { Joint } \\
\text { Venture }\end{array}$ & $\begin{array}{l}\text { Strategic } \\
\text { Alliance }\end{array}$ & \begin{tabular}{|c|} 
Virtual \\
Organization
\end{tabular} \\
\hline Memory & $\begin{array}{l}\text { (Tulving, 1983); } \\
\text { (Vollrath et al., } \\
\text { 1989) }\end{array}$ & $\begin{array}{l}\text { (Vollrath et al., } \\
\text { 1989); } \\
\text { (Klimoski, } \\
\text { 1994); } \\
\text { (Massey et al., } \\
\text { 1996); } \\
\text { (Satzinger, } \\
\text { 1999) }\end{array}$ & $\begin{array}{l}\text { (Walsh and } \\
\text { Ungson, 1991); } \\
\text { (Stein, 1995); } \\
\text { (Stein and } \\
\text { Zwass ,1995); } \\
\text { (Jeffrey, 1998); } \\
\text { (Roth, 1998); } \\
\text { (Moorman, 1999) }\end{array}$ & N/A & N/A & N/A \\
\hline
\end{tabular}




\begin{tabular}{|c|c|c|c|c|c|c|}
\hline Learning & $\begin{array}{l}\text { (Argyris and } \\
\text { Schon,1974); } \\
\text { (Kolb, 1984); } \\
\text { (Cohen, 1991); } \\
\text { (Mumford, 1991); } \\
\text { (Kim, 1993); } \\
\text { (Ezey et al., } \\
\text { 1995); } \\
\text { (Martinez, 1999) }\end{array}$ & $\begin{array}{l}\text { (Cohen, et al., } \\
1981) ; \\
\text { (Harmon and } \\
\text { Rohrbaugh, } \\
\text { 1990); } \\
\text { (Donohue and } \\
\text { Jeremy, 1993); } \\
\text { (Lim, 1997); } \\
\text { (McInerney, } \\
\text { 1997) }\end{array}$ & $\begin{array}{l}\text { (Argyris and } \\
\text { Schon,1974); } \\
\text { (Shrivastava, } \\
\text { 1983); } \\
\text { (Fiol et al., 1985); } \\
\text { (Levitt and March, } \\
\text { 1988); } \\
\text { (Huber, 1991); } \\
\text { (March, 1991); } \\
\text { (Mumford, 1991); } \\
\text { (Simon, 1991); } \\
\text { (Kim, 1993); } \\
\text { (Ddgson, 1993); } \\
\text { (Dixon, 1994); } \\
\text { (Miller, 1996); } \\
\text { (Schein, 1996); } \\
\text { (Easterby, 1997); } \\
\text { (Ribbens, 1997); } \\
\text { (Romme, 1997); } \\
\text { (Sinkula, 1997); } \\
\text { (Tsang, 1997); } \\
\text { (Winter, 1997) }\end{array}$ & $\begin{array}{l}\text { Kogut, 1988); } \\
\text { (Lyles, 1988); } \\
\text { (Inkpen and } \\
\text { Crossan, 1995); } \\
\text { (Richter and } \\
\text { Vettel, 1995); } \\
\text { (Cyr and } \\
\text { Schneider, } \\
\text { 1996); } \\
\text { (Steensma, } \\
\text { 1996); } \\
\text { (Barkema, } \\
\text { 1997); } \\
\text { (Makhija, } \\
\text { 1997); } \\
\text { (Shenkar, 1999) }\end{array}$ & $\begin{array}{l}\text { (Pucik, 1988); } \\
\text { (Hamel, 1991); } \\
\text { (Chan and Wong, } \\
\text { 1994); } \\
\text { (Crossan, 1995); } \\
\text { (Gail, 1995); } \\
\text { (Levinson, 1995); } \\
\text { (Osland and } \\
\text { Taprak, 1995); } \\
\text { (Doz, 1996); } \\
\text { (Mowery, 1996); } \\
\text { (Lei, 1997); } \\
\text { (Inkpen, 1998); } \\
\text { (Lane, 1998); } \\
\text { (Larsson, 1998); } \\
\text { (Hjalager, 1999) }\end{array}$ & (Steil et al., 1999) \\
\hline
\end{tabular}

In developing a conceptual learning model for virtual organizations, we will elaborate theories of memory and learning in organizations in Section 2 and 3. We propose a virtual organizational learning model in Section 4, and illustrate its functions in a cyber community in Section 5. We conclude this paper in Section 6.

\section{Organizational Memory}

The collective mind is not only viewed as a composite of individual minds, but also referred as the social process of articulating, exchanging, and sharing information leading to shared interpretations (Halbwachs, 1980). Organizational memory is an instance of collective memory, which relies on knowledge spatially distributed throughout the processes, individuals, and artifacts of the organization and beyond its boundaries (Stein and Zwass, 1995). Organizational memory is vital for the effectiveness and learning of an organization (Duncan and Weiss, 1979).

The four ontological levels of knowledge, individual, group, organization, and inter-organization, differentiate the various memory and meaning structures. Entities within these four ontological levels should keep their own memory, and retain the interaction between entities at the same level to higher ontological levels. Organizational memory is composed of seven bins, individuals, culture, transformations, structures, ecology, external archives, and information, by combining theories from Walsh \& Ungson (1991) and Hackbarth \& Grover (1999). Organizational memory must include direct experiences and observations of individuals in a suitable format that matches individual cognitive orientations and value systems. Organizational culture is a learned way of perceiving, thinking, and feeling about problems that are transmitted by members of the organization to the organization. Transformations are business processes within a firm that occur frequently. Organizational structure must be considered in light of its implications for individual role, and its link with the environment. Individual roles provide a repository in which organizational information can be stored. The actual physical structure or workplace ecology of an organization encodes and thus reveals a great deal of information about the organization. Information provided by information systems is a more tangible form of organizational memory, which represents details of transactions, decisions, and exchanges. 
External archives help recall particular events when an individual's memory fails.

Individual memory consists of declarative and procedural memories. Semantic and episodic memories are known jointly as declarative memory. Semantic memory refers to general knowledge independent from specific events, which is believed to be stored as a network of concepts. Episodic memory contains information about specific individual experiences, including time of event occurrence and context (Tulving, 1983). Procedural memory is a skill-based memory referring to the implicit knowledge of how to do things, which may be accessible only through performance (Stein and Zwass, 1995).

The meaning structure of organizational members can be categorized as private, accessible and collective (Dixon, 1994). The private meaning structure is composed of organizational members' cognitive maps, which they choose to withhold from other members. The accessible meaning structure is built by an individual's cognitive map, which he or she is willing to make available to others. The collective meaning structure is the cognitive maps, which organizational members hold jointly with other members.

In generalizing the related theories of organizational memory, we view memory as a system composed of internal and external components. In an individual memory, the internal component stores declarative and procedural knowledge shown as the middle layer. The lower layer contains private and accessible meaning structures representing some portions of individual memory people withstand to share with others. External component denotes an outlet to gain knowledge through social network or knowledge mapping system supported by information technology. Modified from Walsh and Ungson's six bins of organizational memory (1991), we assign five bins of organizational memory, culture, ecology, transformation, structure, and individual in the middle layer, and allocate external archives into external component. The individual bin is centered to represent individual memory within the virtual organization. The external archives link to relevant sources such as other members of participant organizations through social network or knowledge mapping system embedded in virtual organizational learning system. When collaborative relationship is terminated, virtual organizational memory is retained mostly through the individual and external archives bins, and the strength of social network may decay.

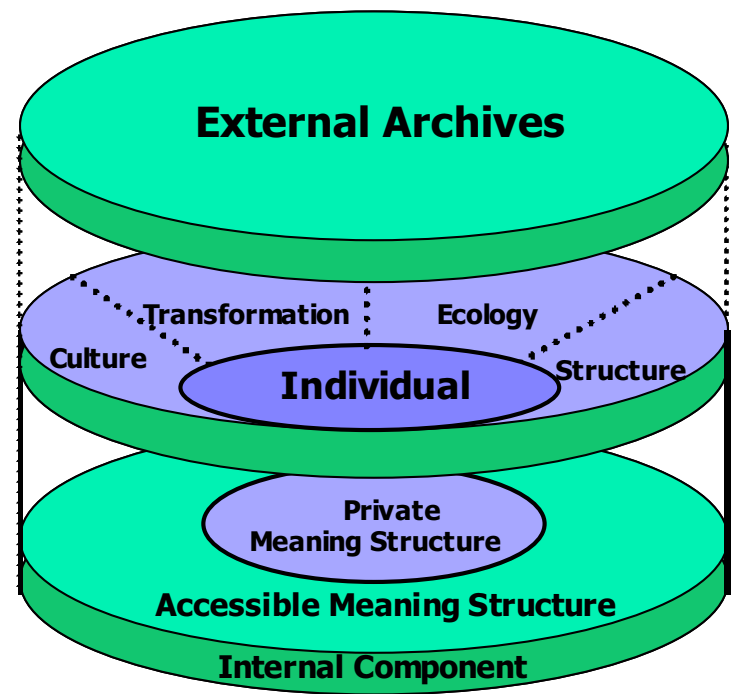

Figure 2. The Structure of Organizational Memory

There are five mnemonic functions, acquisition, retention, maintenance, search, and retrieval, 
to manipulate the organizational memory. Acquisition gathers the data, information, and knowledge from all available sources; retention is the locations that composes the structure of memory; memories must be maintained to make accessible by the way such as to decide how and when to update or delete files; the search function seeks more information, which updates, corrects, or adds to the organizational base; retrieval is the process which organizational memory can be called forth to support decision-making and problem solving (Krippendorff, 1975; Walsh and Ungson, 1991; Stein and Zwass, 1995; Hackbarth and Grover, 1999).

\section{Organizational Learning}

An organization is composed of individuals, and an organization ultimately learns via its individual members (Kim, 1993). For organizational learning to occur, Dixon (1994) pointed out it is not enough by simply encouraging organizational members to exchange their accessible meaning structures with each other; the organization must actively facilitate collective learning. He proposed an organizational learning cycle model as a cycle of generating, integrating, interpreting and acting on information. It consists of four steps: (1) widespread generation of information, (2) integration of new/local information into the organization context, (3) collective interpretation of information, and (4) having authority to take responsible actions based on the interpreted meaning.

Kim (1993) views transfer mechanism between individual and organization as the heart of organizational learning. Nonaka (1994) proposes the SECI model of knowledge creation, which treats the transference between individual and organization as a spiral process interflowing with tacit and explicit knowledge. The SECI model contains four knowledge conversion processes:

(1) Socialization enables the sharing of tacit knowledge between individuals, and emphasizes that tacit knowledge is exchanged through joint activities, such as apprentices work with their mentors and learn craftsmanship not through language but by observation, imitation, and practice.

(2) Externalization requires the expression of tacit knowledge and its translation into comprehensible forms that can be understood by others. Self-transcendence is a key to group integration and the conversion of tacit knowledge to explicit knowledge.

(3) Combination creates new explicit knowledge from explicit knowledge through social processes to combine different bodies of explicit knowledge held by individuals. The key issues are mainly in the communication, diffusion and systemization of knowledge transcending the group.

(4) Internalization converts explicit knowledge to tacit knowledge, and embodies the explicit knowledge by using simulations or experiments to trigger the learning-by-doing process.

Figure 3 illustrates the spiral model of knowledge creation from individual, group, organization, to inter-organizational level. The tacit knowledge embedded with individuals is the basis of organizational knowledge transfer and creation. Through externalization, an individual tacit knowledge can be conceptualized as explicit knowledge. In combining explicit knowledge across individual and organizational boundaries, knowledge can be synthesized into more systematic and executable instructions. During executing the instructions, individuals in the business processes internalize these coded instructions as tacit skills, which are possessed by individuals. The knowledge conversion cycle strengthens the problem solving capability of the organizations, and in turn, renders a paradigm of learning organizations. 


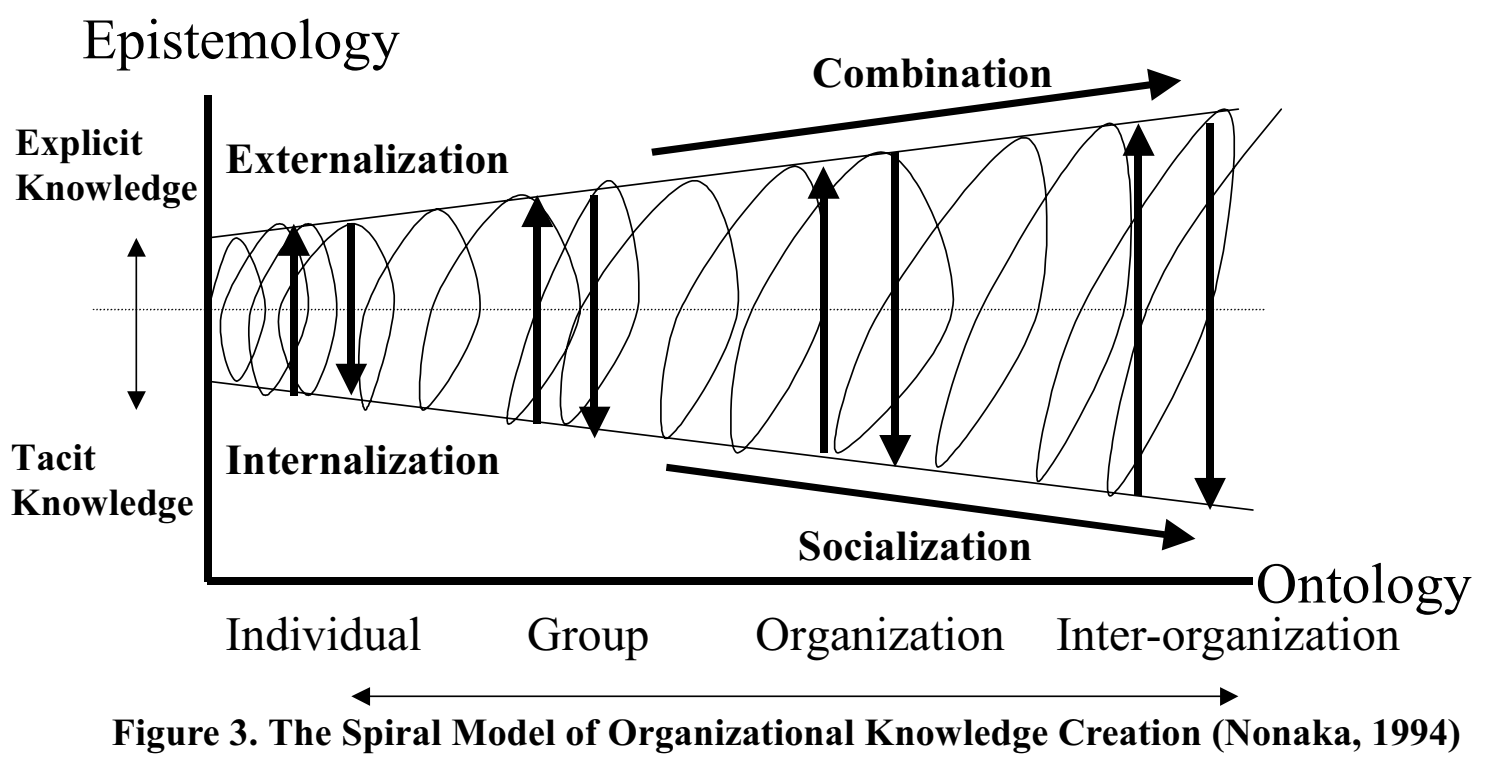

\section{Virtual Organizational Learning Model}

\subsection{Learning in a Virtual Organization}

Learning in a virtual organization can be distinguished from other inter-organizational learning (e.g., strategic alliance) by two characteristics: information technology orientation and social network augmentation. The former refers to considerable exploitation of information technologies in virtual organizations and thus facilitates more explicit knowledge transferred and captured easily; the latter corresponds to its shorter longevity collaborating with participants compared with strategic alliances, but not as short as one-shot contact to diminish the chance of germinating the trust, and thereby contributes to better opportunity to augment their social networks as well (Meyerson, Weick, and Kramer, 1996).

A social network can be defined as a set of nodes (e.g., persons, organizations) linked by a set of social relationships (e.g., friendships, transfer of funds, overlapping membership) (Laumann, Galaskiewicz, and Marsden, 1978). The social network can be assumed as the individual bin (nodes) combined with external archives bin facilitating the sourcing of knowledge.

To facilitate learning in virtual organizations, one question is how to integrate partial knowledge of individuals from different organizations. We face the problem of gathering and coordinating these fragments to form a coherent and complete knowledge to solve problems in a virtual organization. Thus, the following concepts may help elaborate learning in a virtual organization: knowledge map, skills-based management, and transactive memory.

The concept of knowledge map is derived from influence diagrams capturing the diverse information possessed by an individual or a group (Howard and Matheson, 1984). A knowledge map is the visual display of captured information and relationships, which enables the communication and learning of knowledge by observers with differing backgrounds at multiple levels of detail (Edmond, 1999; Howard, 1989; Merkhofer, 1990). The individual items of intellectual capital included in such a map can be text, stories, graphics, models, or 
numbers. Maps can also serves as links to more detailed knowledge sources as well as pointers to implicit knowledge such as experts. An effective knowledge map must evolve through actions and remain up-to-date. They must also be able to exploit this intellectual capital by making this knowledge accessible to everyone at every level of the organization in appropriate forms of display (Edmond, 1999).

Another important concept to facilitate learning in virtual organizations is skill-based management (SBM). Skills-based management proposed by Riehl (1998) advocates a skill inventory application with such components as skills, competency ratings, position profiles, employee profiles and learning events. The SBM application can identify an employee's skill gaps, the distance between the needed skill level and the current skill possessed by the employee. It also facilitates the understanding of relationships between skills and business goals through measures, and then traces and combines skills into job descriptions. The most important objective of SBM is to instill an individual with a greater responsibility for developing his or her valued skills by providing the information resources to define, measure and achieve the goal. The SBM is thought more suitable than knowledge mapping for single-discipline and task-oriented jobs (Kerr, 1998).

The other concept can be applied to virtual organizational learning is transactive memory (Wegner, 1986). Transactive memory describes how people in close relationships share cognition, which means a shared system for encoding, storing, and retrieving information. Transactive memory systems have two major components: (1) the individual memories of the members and (2) the transactive processes that construct and use these individual memories in order to provide the group access to a larger pool of knowledge collectively (Wegner, 1986). For example, a husband may not know where to find candles around the house, for instance, but may still be able to find them in a blackout by asking his wife where the candles are. The transactive process starts when individuals learn something about each other's domains of expertise, and thus enables the group to perform as in an efficient memory system. A directory-sharing computer network is used as a model for describing a transactive memory system (Wegner, 1995). It consists of three key processes: (1) directory updating whereby people learn what others are likely to know, (2) information allocation, by which new information is communicated to the person whose expertise will facilitate its storage, and (3) retrieval coordination, which is a plan for retrieving needed information on any topics based on related knowledge from individual expertise in the memory system.

\subsection{Virtual Organizational Learning Model}

In this subsection, we propose a virtual organizational learning (VOL) model to formally elaborate learning in a virtual organization. By proposing VOL model, we hope to fill the vacancy of learning and memory in virtual organizations denoted in Table 1 . We view a VOL model as a transactive memory system, and a transactive memory system is defined as a three-tuple system:

$T_{\text {mem }}=\left\langle K_{\text {map }}, S_{\text {net }}, M_{\text {fun }}\right\rangle$, where $T_{\text {mem }}$ denotes transactive memory,

$K_{\text {map }}=\left\langle K_{o b j}, K_{d e p}\right\rangle$ denotes knowledge map represented by knowledge objects $\left(K_{o b j}\right)$ and the dependency between knowledge objects $\left(K_{d e p}\right)$,

$S_{n e t}=\left\langle I, R, S_{\text {link }}\right\rangle$ denotes social network formed with individuals $(I)$, their relationship $(R)$, and the strength of the relationship $\left(S_{\text {link }}\right)$, and

$M_{\text {fun }}=\left\langle K_{\text {allocate }}, S_{\text {update }}, K_{\text {maintain, }}, R_{\text {collaborate }}\right\rangle$ represents mnemonic functions including knowledge allocation $\left(K_{\text {allocate }}\right)$, social network updating $\left(S_{\text {update }}\right)$, knowledge maintenance $\left(K_{\text {maintain }}\right)$, and collaborative knowledge retrieval $\left(R_{\text {collaborat }}\right)$. 
Figure 4 illustrates the proposed VOL model. Individuals with individual memory systems from different organizations form a virtual organization, where individual memory contains declarative and procedural knowledge by the meaning structure in various private and accessible degrees. Through external components of individual memory system, which connects together as a social network, we hope to generate the collective meaning structure by linking complementary core competencies of participants.

In the VOL model, a knowledge map captures the knowledge covered in a virtual organization. It is represented by ontology in context (e.g., enterprise ontology) and content (e.g., domain ontology) to link knowledge type and their dependencies in certain business processes. We propose four main mnemonic functions, which compose the knowledge mapping system, in order to manage knowledge map in a virtual organization.

(1) Knowledge allocation function, which links knowledge objects of knowledge maps to individuals of social networks, so that specific knowledge can be allocated through social networks. Agent-based technologies (e.g. Tu and Hsiang, 1998) and skills-based management can be applied here.

(2) Social network updating function, which refresh the relationship between individuals during the interaction along the evolution of a virtual organization. Technologies as data mining in conjunction with skills-based management concepts, and multi-agent system (e.g. Socialware - Hattori, et al., 1999) are suitable for the task.

(3) Knowledge maintenance function, which maintains the knowledge map from performing business processes in a virtual organization by inserting, modifying, or deleting knowledge objects and their dependencies. Bayesian networks (e.g. Howard, 1989), automatic thesaurus generation for ontology construction (e.g. Abecker et al., 1998), and document analysis techniques such as PAT tree (e.g. Ong and Chen, 1999) are applicable.

(4) Collaborative knowledge retrieval function, which retrieves decision models from knowledge maps by collaboratively accessing the transactive memory of individuals. Search engines, Role-Based Access Control (e.g. Hildmann and Bartholdt, 1999), and intelligent information retrieval algorithms can be categorized as relative technologies.

The learning scenarios in the VOL model can be elaborated as follows. Individuals within a virtual organization may initially perform their tasks by utilizing their existing expertise stored in human mind or their organizational memory systems. Since a virtual organization is usually formed by organizations with complementary core competencies, it is common that individuals need to coordinate and collaborate in performing joint business processes. The knowledge allocation function constructs knowledge maps that capture the diverse information possessed by an individual across organization boundaries. Technologies such as information retrieval, text mining, and data mining can be used for constructing knowledge maps. Once the knowledge maps are portrayed, individuals may detect the deficiency and learn to augment individual memory and organizational memory as well. The network updating and knowledge maintenance functions support such augmentation process. The collaborative knowledge retrieval function acquires the decision alternatives in facilitating the problem solving process in a virtual organization. The continued augmenting process of learning is expressed as single- and double-loop learning in VOL model in Figure 4. 


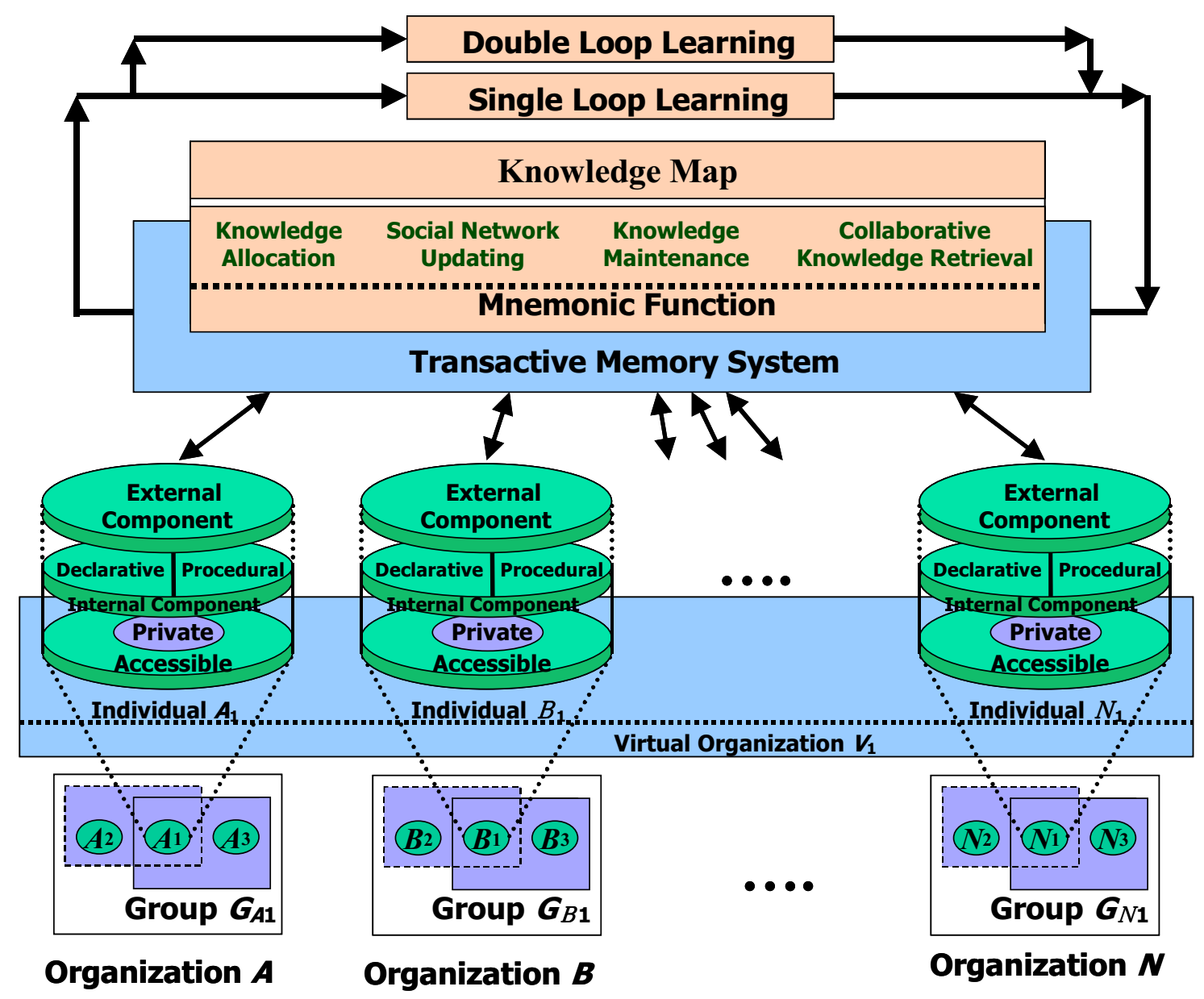

Figure 4. A Virtual Organizational Learning Model

We think transactive memory system is an important mechanism to accelerate learning in virtual organizations. The merits of transactive memory are identified as below:

(1) Knowledge map can be created quickly and maintained easier in a virtual organization: As a "temporary and quickly-formed network", members in virtual organizations may encounter several situations to take part in a totally new-formed group. Rulke and Rau (1997) find that newly formed groups spent time discussing their expertise. Hollingshead (1998) also learned from a laboratory experiment that when communication is allowed, strangers begin to develop transactive memory system by explicitly establishing relative expertise when working on a knowledge-pooling task. Knowledge map can be created quickly and maintained easier in virtual organizations, where business processes mostly operate upon IT-supported platforms, and explicit knowledge is easier captured into knowledge map.

(2) Relative expertise of members in a virtual organization can be easily identified: Members with different expertise may spatially distribute in organizations. Also, each person needs an accurate representation to know who to ask for needed information (Hollingshead, 1998; Wegner, Erber, and Raymond, 1991). Social network works as a directory to relative expertise of members in virtual organization, and thus enables members to know who knows what and where to find the right person to ask. The social network updating function refreshes the continuously evolving organizational memory, and enables employees to learn through navigating the network, as well as through the discovery of new relationships (Edmond, 1999).

(3) Facilitate faster job training and role orientation for individuals in a virtual organization: When new individuals or reassigned employees come in, they have no connections to the virtual organizational memory. With a transactive memory system, 
workers can orient themselves by identifying their organizational roles, then navigating to their assigned responsibilities, the available support resources, and then on to views of the rest of the enterprise to learn how it really works (Edmond, 1999). It also prevents fragmented learning proposed by Kim (1993) from taking place in virtual organizations.

(4) Provide integrated and relevant knowledge to members in a virtual organization: An individual's ability to integrate knowledge is constrained by cognitive limits, and it is not feasible for each individual to try to learn all knowledge possessed by other specialists (Grant, 1996). With the help of collaborative knowledge retrieval function of a transactive memory system supported by various IT, knowledge fall into the same category can be integrated and relevant knowledge about events of interest can be also accessed.

(5) Make mental model explicit and allow people with expertise in many different domains in a virtual organizations to communicate with each other: Knowledge map is a tool or language to make shared mental model explicit, it permits gradual collection of knowledge in an increasing quantitative form, and thus allows people with expertise in many different domains to communicate with each other and to contribute their knowledge to solving problems (Howard, 1989). As mental models are made explicit and actively shared, the base of shared meaning in an organization expands, the organization's capacity for effective coordinated action increases, it may accelerate individual learning as well (Kim, 1993).

(6) Encourage people to share knowledge with others: Since the relationships in social network are identified explicitly and people are upheld as 'experts' in specific domains, they may feel responsible to provide requested knowledge to solve problems. People may also feel free to ask 'stupid' questions because asking for someone's help is what the social network subsystem inspires to do.

\section{VOL Model in Cyber Community}

As we mentioned in Section 4 that virtual organizational learning is more information technology orientation and social network augmentation, a cyber community lays out a great foundation for forming virtual organizations. The VOL model proposed in this paper can be developed as a VOL system in cyber communities to facilitate the learning process.

Figure 5 lays out how a VOL system exists in a cyber community, where individuals come from physical organizations. Through social networks growing in the cyber community, individuals get to know each other in the virtual space, and of course, individual's mutual acquaintances may be enhanced or withheld by the physical connections. According to the four stages of life cycle of a virtual organization as shown in Figure 1, the social networks embedded in a cyber community may facilitate the identification and formation of a virtual organization. During the operation stage of a virtual organization, the VOL system with transactive memory facilitates the learning cycle in the virtual space to improve the performance of business processes. The termination of a virtual organization 


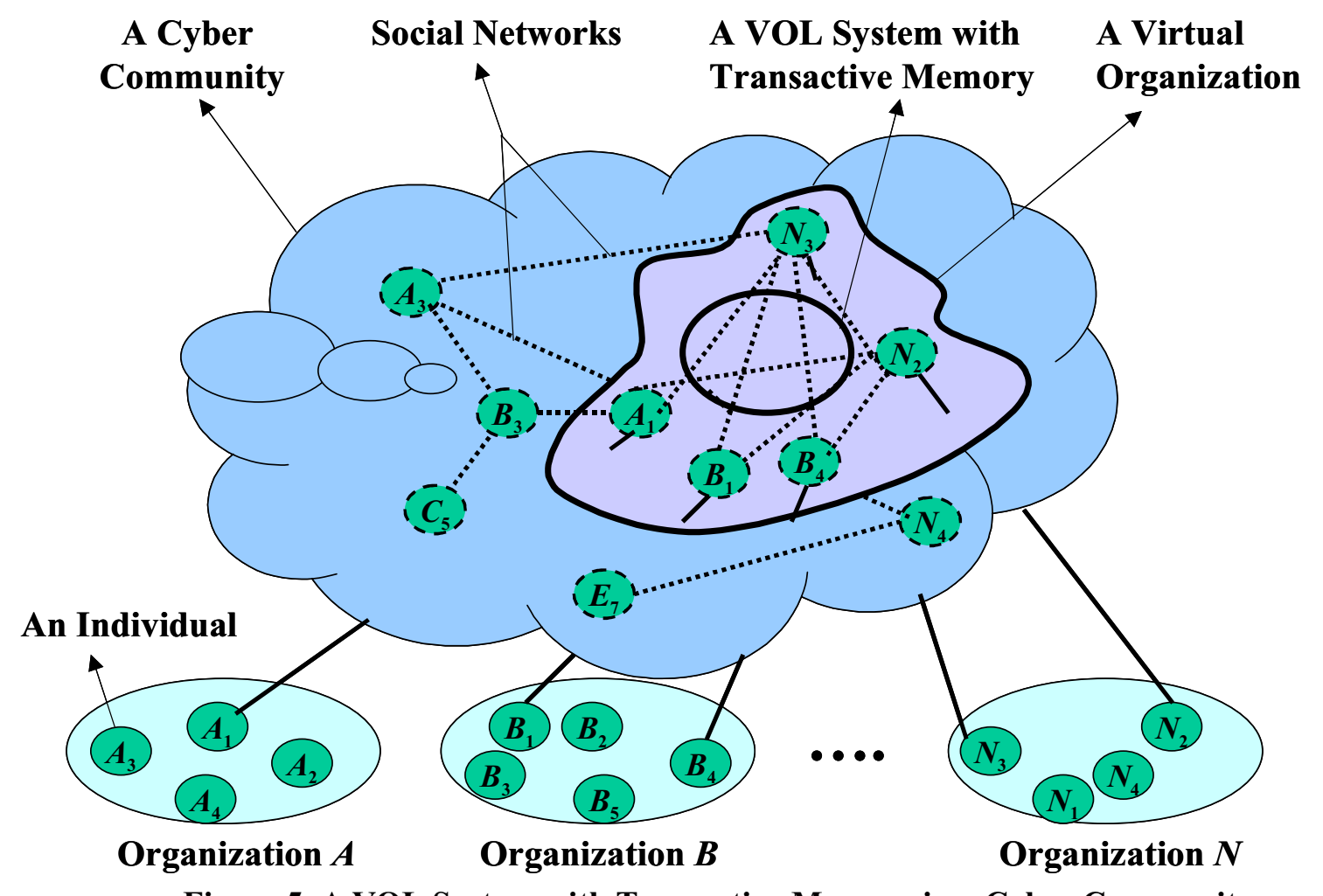

Figure 5. A VOL System with Transactive Memory in a Cyber Community

signifies the "forgetting" of the transactive memory due to stopping memory refresh and recall.

Specifically, we can further dichotomize the learning in a virtual organization into three approaches: information sharing, knowledge mapping, and social networking (shown in Figure 6). This viewpoint is based on the transfer of tacit and explicit knowledge between organizations in a cyber community, elaborated by Nonaka (1998) to capitalize market knowledge. Knowledge transferred between participant companies consists of complementary and compatible knowledge bases. With the first approach, knowledge transfer is enabled through sharing information when both parties codify their knowledge into information. With the second approach, the transference of tacit knowledge of participating firms is facilitated by knowledge mapping system described in the VOL model to convert tacit knowledge to explicit knowledge. With the third approach, the transference of tacit

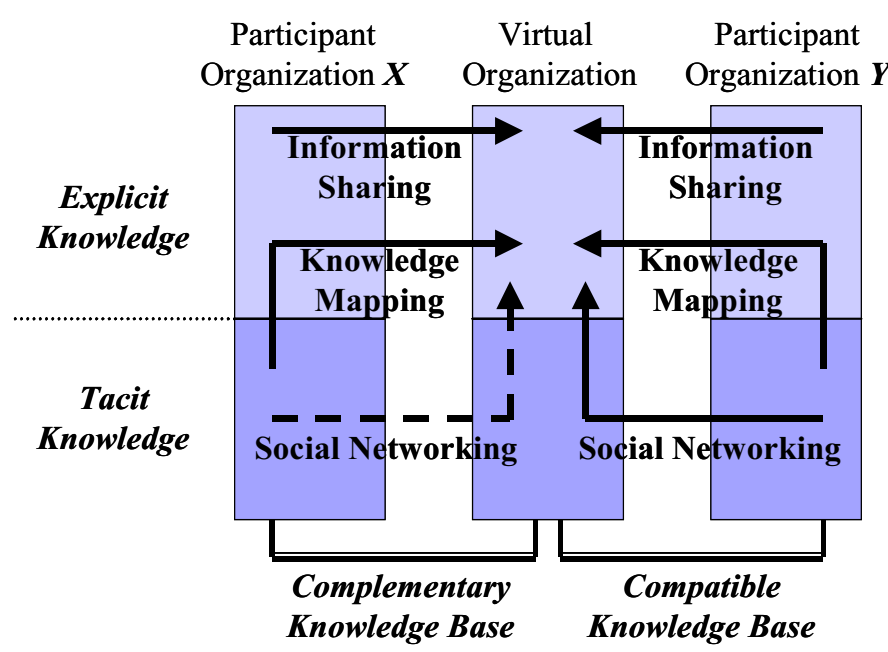

Figure 6. Knowledge Transference in Virtual Organizational Learning 
knowledge is triggered by socialization proposed by Nonaka (1994), perhaps through apprenticeship to transfer knowledge. However, participants with complementary knowledge due to lack of absorptive capacity (identified by Cohen and Levinthal, 1990) may encounter higher hurdle in learning drawn by the dash line in Figure 6. Besides, different industries may prefer different learning approaches. For industries mostly facing structured problems, such as the provision of mature or standard products, may heavily depend on the knowledge mapping and information sharing approaches than social networking, since the captured knowledge is reusable. For industries mainly resolve unstructured problems, articulating the involved knowledge may be a tough or costly task, so that the social networking approach can deliver significant benefits.

\section{Conclusions}

This paper proposes a conceptual model, the VOL model, for elaborating learning in a virtual organization, and elaborates the VOL systems, especially, in a cyber community. The transactive memory composed of social network, knowledge map, and mnemonic functions is a suitable mechanism for developing virtual organizational memory. Based on knowledge conversion across individual and organization, the VOL system can serve as the core technology in synthesizing tacit or explicit knowledge from organizations with complementary or compatible knowledge bases.

In future research, we will further develop the components and functions for a transactive memory system for specific business applications and cyber communities. Through the implementation, we can revise the VOL model to make it more feasible for facilitating learning in virtual organizations. The formulation of knowledge-sharing culture, concerns of privacy and security in social network construction, and the role of inter-organizational memory are also interesting issues for further studies.

\section{References (contact the authors for references in Table 1)}

Abecker, A., Bernardi, A., Hinkelmann, K., Kuhn, O., and Sintek, M. "Toward a Technology for Organizational Memories," IEEE Intelligent Systems (13:3), 1998, pp.40-48.

Balakrishnan, S., and Koza, M. P. "Information Asymmetry, Adverse Selection and Joint Ventures," Journal of Economic Behavior and Organization (20), 1993, pp.99-117.

Bottoms, D. "Back to the Future," Industry Week (243:18), 1994.

Chesbrough, H. W., and Teece, D. J. "When Is Virtual Virtuous? Organizing for Innovation," Harvard Business Review (74:1), 1996, pp.65-72.

Cohen, W., and Levinthal, D. "Absorptive Capacity: A New Perspective on Learning and Innovation," Administrative Science Quarterly (35), 1990, pp.128-152.

Dixon, N. M. The Organizational Learning Cycle: How We Can Learn Collectively, McGraw-Hill, 1994.

Duncan, R., and Weiss, A. "Organizational Learning: Implications for Organizational Design," in Research in Organizational Behavior, B. Staw (Ed.), (1), 1979, pp.75-123, CT, 
Greenwich: JAI Press.

Edmond, F. Vail III "Knowledge Mapping: Getting Started with Knowledge Management," Information Systems Management, Fall 1999, pp.16-23.

Goldman, S. L., Nagel, R. N., and Preiss, K. Agile Competitors and Virtual Organizations: Strategies for Enriching the Customer, 1995, New York: Van Nostrand-Reinhold.

Grant, R. M. "Prospering in Dynamically-competitive Environments: Organizational Capability as Knowledge Integration,” Organization Science (7:4), 1996, pp.375-387.

Hackbarth, G., and Grover, V. "The Knowledge Repository: Organizational Memory Information Systems," Information Systems Management, Summer 1999, pp.21-30.

Halbwachs, M. The Collective Memory, F. J. Ditter and V. Y. Ditter (Eds.) (translation of 1950 original) , 1950/1980, New York: Harper Colophon.

Hattori, F., Ohguro, T., Yokoo, M., Matsubara, S., and Yoshida, S. "Socialware: Multiagent Systems for Supporting Network Communities," Communication of the ACM (42:3), 1999, pp.55-61.

Hildmann, T., and Bartholdt, J. "Managing Trust between Collaborating Companies Using Outsourced Role Based Access Control," In Proceedings of the fourth ACM workshop on Role-based access control, 1999, pp. 105-111.

Hollingshead, A. B. "Retrieval Processes in Transactive Memory Systems," Journal of Personality and Social Psychology (74:3), 1998, pp.659-671.

Howard, R. A., and Matheson, J. E. "Influence Diagrams," Readings on the Principles and Applications of Decision Analysis, Vol. II, Strategic Decisions Group, Menlo Park, CA, 1984.

Howard, R. A. “Knowledge Map,” Management Science (35:8), 1989, pp.903-922.

Kerr, J. “Brain Inventories,” Software Magazine (18:11), 1998, pp.16.

Kim, D. H. "The Link between Individual and Organizational Learning," Sloan Management Review (35:1), Fall 1993.

Krippendorff, K. "Some Principles of Information Storage and Retrieval in Society," General Systems (20), 1975, pp.15-35.

Laumann, E. O., Galaskiewicz, J., and Marsden, P. V. "Community structure as inter-organizational linkages," Annual Review of Sociology (4), 1978, pp.455-484.

Lin, F.-R., and Shaw, M. J. Reengineering the Order Fulfillment Process in Supply Chain Networks, International Journal of Flexible Manufacturing Systems (10:3), 1998, pp. 197-229.

Merkhofer, M. W. "Using Inference Diagrams in Multiattribute Utility Analysis-Improving Effectiveness Through Improving Communication,” in R.M. Oliver and J. Q. Smith (Eds.), 
Influence Diagrams, Belief Nets and Decision Analysis, 1990, New York: Wiley.

Meyerson, D., Weick, K. E., and Kramer, R. M. Swift trust and temporary groups. In Kramer, R. M. and Tyler, T. R. (Eds.), Trust in organizations: Frontiers of theory and research, 1996, pp. 166-195, Thousand Oaks, CA: Sage Publications.

Nonaka, I. "A Dynamic Theory of Organizational Knowledge Creation," Organization Science (5:1), Feb 1994, pp.14-37.

Ong, T. H., and Chen, H. "Updateable PAT-Tree Approach to Chinese Key Phrase Extraction using Mutual Information: A Linguistic Foundation for Knowledge Management," In Proceedings of the Second Asian Digital Libraries Conference, 1999.

Riehl, H. "Managing with Skills," Ivey Business Journal (62:4), 1998, pp.50-54.

Rulke, D. L., and Rau, D. "Examining the Encoding Process of Transactive Memory in Group Training," Academy of Management Proceedings, 1997, pp.349-353.

Stein, E. W., and Zwass, V. "Actualizing Organizational Memory with Information Systems," Information Systems Research (6:2), 1995, pp.85-117.

Shenkar, O., and Li, J. "Knowledge Search in International Cooperative Ventures," Organization Science (10:2), 1999, pp.134-143.

Strader, T. J., Lin, F. R., and Shaw, M. J. "Information Infrastructure for Electronic Virtual Organization Management," Decision Support Systems (23), 1998, pp.75-94.

Tu, H. C., and Hsiang, Jieh. "An Architecture and Category Knowledge for Intelligent Information Retrieval Agents," In Proceedings of the 31st Hawaii International Conference on System Sciences (HICSS'98), IEEE, 1998.

Tulving, E. Elements of Episodic Memory, 1983, Oxford: Oxford University Press.

Walsh, J. P., and Ungson, G. R. "Organizational Memory," Academy of Management Journal (16:1), 1991, pp.57-91.

Wegner, D. M. "Transactive Memory: A Contemporary Analysis of the Group Mind," In B. Mullen \& G. R. Goethals (Eds.), Theories of Group behavior, 1986, pp.185-208, New York: Springer-Verlag.

Wegner, D. M., Erber, R., and Raymond, P. "Transactive Memory in Close Relationships," Journal of Personality and Social Psychology (61), 1991, pp.923-929.

Wegner, D. M. “A Computer Network Model of Human Transactive Memory," Social Cognition (13), 1995, pp.319-339. 